\title{
Public College Students' Perception of Underage Drinking In Nigeria: Analysis of Current Issues
}

\author{
Olujide A. Adekeye ${ }^{1}$, Florence Omumu ${ }^{2}$, Olufunke O. Chenube ${ }^{3}$, Emmanuel O. Amoo, \\ Sussan O. Adeusi ${ }^{1} \&$ Muyiwa A. Solarin ${ }^{1}$ \\ ${ }^{1}$ Covenant University, Department of Psychology, Ota, Nigeria \\ ${ }^{2}$ Delta State University, Department of Counselling Psychology, Abraka, Nigeria \\ ${ }^{3}$ College of Education, Early Childhood Unit, Agbor, Nigeria \\ ${ }^{4}$ Covenant University, Demography and Social Statistics, Ota, Nigeria \\ Correspondence: Olujide A. Adekeye, Department of Psychology and University Counselling Centre, Covenant \\ University, Ota, Nigeria. Tel: 234-803-595-6630.
}

Received: April 13, 2019 Accepted: May 30, 2019 Online Published: June 25, 2019

doi:10.5539/gjhs.v11n7p164

URL: https://doi.org/10.5539/gjhs.v11n7p164

\begin{abstract}
Background: Alcohol is the most widely used substance of abuse among youths in Nigerian. Currently, underage drinking has become a serious public health problem in most colleges and despite the health and safety risk, consumption of alcohol is rising. Having recourse to the public health objective on alcohol by the World Health organization, which is to reduce the health burden caused by the harmful use of alcohol, thereby saving lives and reducing injuries, this study explored the nature of alcohol use among college students, binge drinking and the consequences of alcohol consumption. Secondary school students are in a transition developmentally and this comes with its debilitating effects such as risky alcohol use which affects their health and educational attainment (Loukas, Cance, \& Batanova, 2016; Adekeye, 2012).

Methods: This is a cross-sectional study of 809 college students (ages 14-20 years) using the research survey method. For data collection, an adapted and validated version of the youth questionnaire on underage drinking was employed.

Results: Bivariate analysis found that more male students consume beer and spirits while wine was the reported preference of female students. Heavy episodic drinking (HED) was discovered among few male students while $50.2 \%$ of the sample had their first drink between ages 14 and $17.81 \%$ of the sample had ever drank alcohol while more than half (65\%) of the sample consume alcohol once in a month. Further analyses show prevalence of alcohol consumption, strategies to reducing alcohol use, reasons for underage drinking and effects of alcohol consumption.

Conclusions: A majority of underage students supported increasing efforts to control underage drinking. The students reported that an effective approach to decreasing alcohol use could be public presentations by people who have been seriously hurt or impaired by alcohol use. This will be a veritable public health intervention.
\end{abstract}

Keywords: Alcohol, college, underage drinking, youths, perception

\section{Introduction}

Alcohol use and abuse among underage is a growing public health problem in Nigeria and the consequences of underage drinking affects everyone regardless of gender, age or drinking status (Adekeye, Amoo, Adeusi, Chenube, Ahmadu, \& Idoko, 2019). These effects could manifest in acts of aggressive behaviour, arson, property damage, injuries, risky sexual behaviour, violence, and deaths. Underage drinking is now pervasive that its influence goes beyond family setting. It is a nationwide cum global issue. Alcohol can be misused because it is available in different forms and easily accessible; in some countries and society, its consumption is legal as it is perceived as a social drink. However, Keller and Vaillant (2011) noted that if consumed moderately, alcohol could have positive health outcomes.

Some underage drinking statistics in the United States show that young people consume alcohol. Report from SAMHSA (2016a) revealed that at 15years, a third of teens (33\%) have had at least 1 drink. This increased to $60 \%$ by age 18 . In 2015, SAMHSA (2016b) reported that 7.7 million young people (12-20 years) reported that they 
drank alcohol beyond "just a few sips" in the past month. In the United States, young people (12-20 years) drink $11 \%$ of all alcohol consumed yearly. The report further stated that adults consume more alcohol than youths; but when youths drink, they consume more at once, through binge drinking (CDC, 2016). There is almost the same level of prevalence of drinking between young boys and girls, but often among older teenagers, more boys than girls engage in binge drinking.

As noted by Grant and Dawson (1997), the lifetime prevalence of alcohol dependence is more than $40 \%$ among those who initiated drinking at the age of 14years or earlier. However, the percentage decreases with older age of initiation. Young adults above 20 years have about 10 percent probability to misuse and abuse alcohol or to turn an alcoholic in their lifetime. To corroborate this, Jernigan (2001) noted that there is more empirical evidence to suggest that those who are initiated too early into the drinking culture end up abusing and misusing alcohol and they experience more alcohol-related injury during lifetime than those who start drinking in later life. Adolescence period is a developmental stage of life normally characterized by experimentation, risk-taking, sexual exploration, drug use and consequently drug abuse (Adekeye, 2005). During this stage of life, there may be poor attitude to life, behavioural issues that may affect educational attainment and health may develop (Loukas, Cance, \& Batanova, 2016; Morgan \& Todd, 2009). Results from the Middle School Youth Risk Behavior Survey for "ever drank alcohol" show a prevalence of $20.5 \%$ for seventh graders and $30.5 \%$ for eighth graders (CDC, 2015).

Alcohol consumption has been a source concern in many societies however; underage drinking is a huge source of concern globally due to the impact on the under-aged individual which adversely affects the future of any nation (Adekeye, Adeusi, Chenube, Ahmadu, \& Sholarin, 2015). Recently, Guinness Nigeria rolled out campaign against under-age drinking in Lagos Schools' using drama and interactive educational tools to enable pupils toappreciate the dangers of alcohol consumption, dangers, and the effects of alcohol use, misuse and abuseg (Okeh, 2018).

In Nigeria, a wide variety of substances have been and are still in use despite the growing body of evidence of serious health risks associated with unauthorized administration of psychoactive substances (Adekeye, Odukoya, Chenube, Igbokwe, Igbinoba, \& Olowookere, 2017). According to Guardian Newspapers (2018), availability and easy access (at bars and liquor stores) to alcohol resulted to increased alcohol consumption. Availability and easy access is fueled by the production of locally brewed alcoholic beverages. This is often done in the hinterland, far from the sight of regulating authorities. Information Services Division, Scotland (2014) revealed prevalence of $32 \%$ for 13 -year-olds and $70 \%$ for 15 -year-olds while in England, underage drinking remains fairly prevalent. 38\% of teens (11-15-years) have consumed alcohol though the rate is higher among older teens (16 and 17-years) (Health and Social Care Information Centre (HSCIC, 2015).

Apart from age, the prevalence of alcohol drinking can also be appreciated by looking into gender and socio-economic groups. HSCIC (2015) revealed that young teen males and females drink at the same level till about age 16 . At age 16 , males are much more likely to drink. It was reported that about $64 \%$ of 17 -year-old boys and about $48 \%$ of girls drink weekly. The relationship between socioeconomic status and underage drinking is less clear. In Nigeria, children from both deprived and privileged homes consume alcohol, the difference being the type and quality of the drink. Children from local communities and less privileged homes consume more of locally brewed drinks or inferior quality beers and other distilled products which are readily available and relatively cheap. However, children from privileged and affluent homes consume more of wines, spirits and good quality beers. In England for example, teens from low socio-economic families drink less compared to teens from high socio-economic families while in Scotland, there is no distinct difference in underage alcohol consumption based on socio-economic status. It was further revealed that there are substantial differences in the rate of underage drinking across different ethnicities. Of the 11-15-years sampled, $42 \%$ were white children, black children (21\%) and $10 \%$ were Asians.

The most recent European School Survey project on Alcohol and other Drugs (ESPAD survey) carried out in 2011 show that young people's drinking in the United Kingdom is well above the European average on a number of metrics (Hibell, Guttormsson, Ahlström, Balakireva, Bjarnason, Kokkevi et al., 2012). In the United Kingdom, a sample of 15-16 year-olds show that $85 \%$ had drank alcohol in the past 12 months with the European average being $79 \%$. Among the same sample in the UK, $65 \%$ had drunk alcohol in the past 30 days with the European average being $57 \%$. Also in the UK, 55\% reported ever having been drunk with the European average being $47 \%$ (Hibell et al., 2012).

Underage drinking has become a recurrent issue in the world today and the sources where the underage get their drinks from remain worrisome. The 2009 Victorian Youth Alcohol and Drug Survey indicate that 58 percent of 16 and 17 year olds tend to drink alcohol at private parties, 53 percent at friend's houses, and 36 percent in their own homes. It was also revealed that less than 7 percent of the survey respondents said they drank alcohol in licensed 
premises, and only 4 percent said they usually drank in public places. Furthermore, it was said that most young people (62\%) got their alcohol from friends or acquaintances, 44 percent said their parents bought it for them, and around one in ten said they bought it themselves, or it was bought for them by a brother or sister.

The inquisitiveness of youths to copy or model after some adult drinking style can sometimes be excused but the danger of underage drinking cannot be over emphasized. It was revealed that when a child begins drinking before age 15, they are much more likely to become long-term drinker, or problem drinker which means they get drunk, have accidents related to drinking, get into trouble with the law, their families, friends, schools, or the people they date (Vorvick, 2016). Ipsos MORI (2016) revealed that $43 \%$ of young people who drink alcohol, have reported that they are drinking to cope in some way, such as to cheer themselves up or to forget about problems, how possible, if not the lies or make believe from their models. Cooper and Orcutt (1997) and Cooper, Pierce, and Huselid (1994) opine that underage drinking plays a significant role in risky sexual behaviour, including unwanted, unintended, and unprotected sexual activity and sex with multiple partners which increases the risk for unplanned pregnancy and promotes contracting of sexually transmitted infections including HIV/AIDS.

\subsection{Objectives of the Study}

This study was designed to bring to the fore the understanding underage drinkers have of alcohol use including perceived consequences of unregulated alcohol use. It is also to explore factors contributing to the problem of alcohol use by the under aged. To achieve the aims of this study, some specific objectives were set such as:

1) To explore the strategies to reducing underage alcohol consumption

2) To evaluate how often underage consume alcohol

3) To examine why underage students drink and the effects of alcohol on underage drinkers

4) To determine among the ever drinkers, the frequency of drinks, and whether alcohol consumption among underage drinkers have increased

\subsection{Research Questions}

1) What are the strategies to reducing underage alcohol consumption

2) How often do underage consume alcohol?

3) Why do underage students drink and what are the effects of alcohol on underage drinkers

4) Among the ever drinkers, what is the frequency of drinks, and has alcohol consumption increased

\section{Methods}

\subsection{Design/Population/Sample and Sampling Techniques}

The design used for this study is the cross-sectional survey design. This study involved participants from some selected secondary schools in Ota, a sub-urban location in Southwest, Nigeria. Participants were selected from across all core areas such as sciences, arts and humanities and business classes through stratified and simple random sampling, to cater for variables such as gender, age, living location, subject area and ethnicity. Characteristics of the participants included a gender mix of 553 males (68.4\%) and 256 females (31.6\%), age ranges from 14 and 20 years (mean age $=16.3$ years, $+/-1.49$ years).

\subsection{Ethical Consideration}

The department of Psychology internal review board (IRB) certified the study fit as not constituting harm to the respondents. Furthermore, parents of the selected participants signed an informed consent form to indicate their approval. School principals of the selected students provided informed consent and conveyed their approval to the researchers in writing. Participants were informed that they were free to participate or to decline participation in the study. Anonymity was assured by asking participants not to write their names on the questionnaire forms.

\subsection{Instruments}

A questionnaire form with items on use of alcohol and perception to underage drinking was used to elicit information from the respondents. The first part of the questionnaire dealt with participants socio-demographic details. In order to ensure the psychometric requirements of the scale as advocated by Odukoya, Adekeye, Igbinoba, \& Afolabi (2018), the reliability of the instrument was established using a test-retest reliability method. It was administered to 30 secondary school students and a second administration after a three-week interval with a Cronbach's Alpha of 0.83 . The research trajectory was therefore considered adequate for data gathering purposes. 


\subsection{Procedure for Data Collection and Analysis}

The questionnaire forms were administered to the participants with the aid of research assistants. The questionnaires were administered and some were collected on the spot while others were retrieved later. Eight hundred and nine of the nine hundred forms were fit for statistical analyses, representing $90 \%$ response rate. The data were expressed as both descriptive and inferential statistics, such as frequency counts, percentages and chi-square analysis to answer the research questions. A p-value of $\leq 0.05$ was considered significant. All statistical analyses were performed using IBM statistical software.

\subsection{Study Participants and Inclusion/Exclusion Criteria}

The respondents comprised 809 senior secondary school students who were selected to participate in the study. The inclusion criteria included that the school principal must provide informed consent in writing; the respondent (student) must be in senior secondary school class, agree to participate freely, inform their parents/guardians about the study, and provide a letter of consent from them. A participant must also be at least 14 years of age and not more than 20 years. Those who did not meet these criteria were excluded from the study.

\section{Results}

\subsection{Demographic Data}

This section shows the data obtained from the study in frequency counts and percentages

Table 1. Demographic characteristics

\begin{tabular}{|c|c|}
\hline Variables & Frequency/Percent \\
\hline \multicolumn{2}{|l|}{ Sex } \\
\hline Male & $553(68 \%)$ \\
\hline Female & $256(32 \%)$ \\
\hline \multicolumn{2}{|l|}{ Age } \\
\hline $14 \mathrm{yrs}$ & $104(13 \%)$ \\
\hline $15-17 \mathrm{yrs}$ & $568(70 \%)$ \\
\hline $18-20 y r s$ & $137(17 \%)$ \\
\hline \multicolumn{2}{|l|}{ Preferred Drink } \\
\hline Beer & Male (401 [92\%]), Female (89 [41\%]) \\
\hline Spirits & Male (353 [81\%]), Female (41 [19\%]) \\
\hline Wine & Male (318 [73\%]), Female (212 [97\%]) \\
\hline \multicolumn{2}{|l|}{ Ethnicity } \\
\hline Yoruba & $618(76.4 \%)$ \\
\hline Igbo & $142(17.6 \%)$ \\
\hline Hausa & $16(2.0 \%)$ \\
\hline Others & $33(4.0 \%)$ \\
\hline \multicolumn{2}{|l|}{ Age at first drink } \\
\hline Less than 10 years & $56(8.5 \%)$ \\
\hline $10-13$ years & $253(38.5 \%)$ \\
\hline $14-17$ years & $330(50.2 \%)$ \\
\hline 18 years and above & $18(2.8 \%)$ \\
\hline
\end{tabular}

Among the respondents in Table 1, 68\% were males. Age ranged from 14 to 20 years. Because the setting was in the Southwestern part of Nigeria, underage from the Yoruba ethnic group made up the majority $(76.4 \%)$ while about half of the sample had their first drink between ages 14 and 17. More male students consume beer (92\%) and spirits $(81 \%)$ while wine $(97 \%)$ was the reported preference of female students. About 39\% had their first drink 
between ages 10 and 13 years while 50.2\% of the sample had their first drink between ages 14 and 17 .

\subsection{Responses to Research Questions}

Research Question 1: Strategies to Reducing Underage Alcohol Consumption

Table 2. Strategies to reducing underage alcohol consumption

\begin{tabular}{lll}
\hline Which of the following approaches would you support to decrease alcohol use by youth? & Frequency/(\%) & Rank \\
\hline New and/or stiffer penalties & $247(30.5 \%)$ & 6 th \\
More law enforcement & $402(49.7 \%)$ & 4 th \\
More alcohol education in schools & $588(72.7 \%)$ & 1 st \\
More alcohol education in the mass media (TV, radio, magazines) & $541(66.9 \%)$ & $2 \mathrm{nd}$ \\
Alcohol-free teen night clubs & $200(24.7 \%)$ & 8 th \\
Public presentations by people who have been seriously hurt or impaired by alcohol abuse & $384(47.5 \%)$ & 5 th \\
Driver's license suspension for youth who drink alcohol & $235(29.0 \%)$ & 7 th \\
Ban on alcohol advertising & $490(60.6 \%)$ & $3 \mathrm{rd}$ \\
\hline
\end{tabular}

Respondents were given some strategies and thereafter asked to pick which of the strategies or approaches they would support in the quest to decreasing alcohol use by the underage (Table 2). Their responses were ranked ordered and about $73 \%$ agreed that there should be more alcohol education in schools while about $67 \%$ felt there should be more alcohol education in the mass media. Others advocated for ban on alcohol advertising $(60.6 \%)$ and about half of the respondents were of the view that more law enforcement (50\%) will reduce alcohol consumption by the underage.

Research Question 2: How often do underage consume alcohol?

Table 3. Frequency of Alcohol consumption

\begin{tabular}{ll}
\hline How often do you drink alcohol? $(\mathbf{n}=\mathbf{6 5 7})$ & Frequency/(\%) \\
\hline Once a Week & $154(23.4 \%)$ \\
Once a Month & $427(65.0 \%)$ \\
More than once a Month & $76(11.6 \%)$ \\
\hline
\end{tabular}

On the frequency of alcohol consumption, 427 (65\%) drink once in a month while 154 (23.4\%) drink once in a week. Only $76(11.6 \%)$ drink more than once in a month. There was little evidence of binge drinking among those who drink as only $54(8 \%)$ of the 657 have had five or more drinks at a time and of the 54, $34(63 \%)$ have had five or more drinks in the last month. 
Research Question 3: Why do underage students drink and what are the effects of alcohol on underage drinkers

Table 4. Reasons for underage drinking and effects of alcohol on underage drinkers

\begin{tabular}{ll}
\hline Why do underage students drink and what are the effects of alcohol on underage drinkers & Frequency/(\%) \\
\hline Underage drink because ---- & $525(26.0 \%)$ \\
They want to have a good time at a party & $478(23.8 \%)$ \\
They are sad or depressed and want to feel better about themselves & $197(10.0 \%)$ \\
They wish to rebel and defy their parents, teachers and other adult authorities & $485(24.2 \%)$ \\
They wish to fit in or be accepted by their friends or peers & $318(16.0 \%)$ \\
They are bored & \\
\hline Effects of Alcohol & $97(22.7 \%)$ \\
Been absent from school & $28(6.6 \%)$ \\
Been drunk at school & $21(5.0 \%)$ \\
Performing poorly in school & $21(5.0 \%)$ \\
Having family problems & $17(4.0 \%)$ \\
Been arrested & $27(6.3 \%)$ \\
Driving under the influence of alcohol & $104(24.4 \%)$ \\
Been driven by a drunk driver (passenger) & $86(20.0 \%)$ \\
Been drunk at a party & $26(6.0 \%)$ \\
\hline Had an injury & \\
\hline
\end{tabular}

As depicted in table 4, the respondents advanced varied reasons for drinking such as having a good time at a party $525(26 \%)$, wishing to fit in or be accepted by their friends or peers $(24.2 \%)$ and because they are sad or depressed and want to feel better about themselves (23.8\%). Respondents were asked if they had experienced some situations due to alcohol consumption. Responses ranged from been a passenger in a vehicle in which the driver was under the influence of alcohol (24.4\%), been absent from school because of alcohol (22.7\%) and been drunk at a party $(20.0 \%)$.

Research Question 4: Among the ever drinkers, what is the frequency of drinks, and has alcohol consumption increased by sex and age

A majority of male (66.7\%) students and respondents between ages 15 and 17 (75.6\%) reported being ever drinkers. Only $33.3 \%$ of female respondents indicate being ever drinkers. In Table 5, there is an association between gender and being ever drinkers. The p-value indicates that these variables are not independent of each other and that there is a statistically significant relationship between the categorical variables. Majority of the ever drank alcohol drink once in a month. 
Table 5. Bivariate Analysis on ever drinkers, frequency of drinks, drinking and driving and whether alcohol consumption has increased

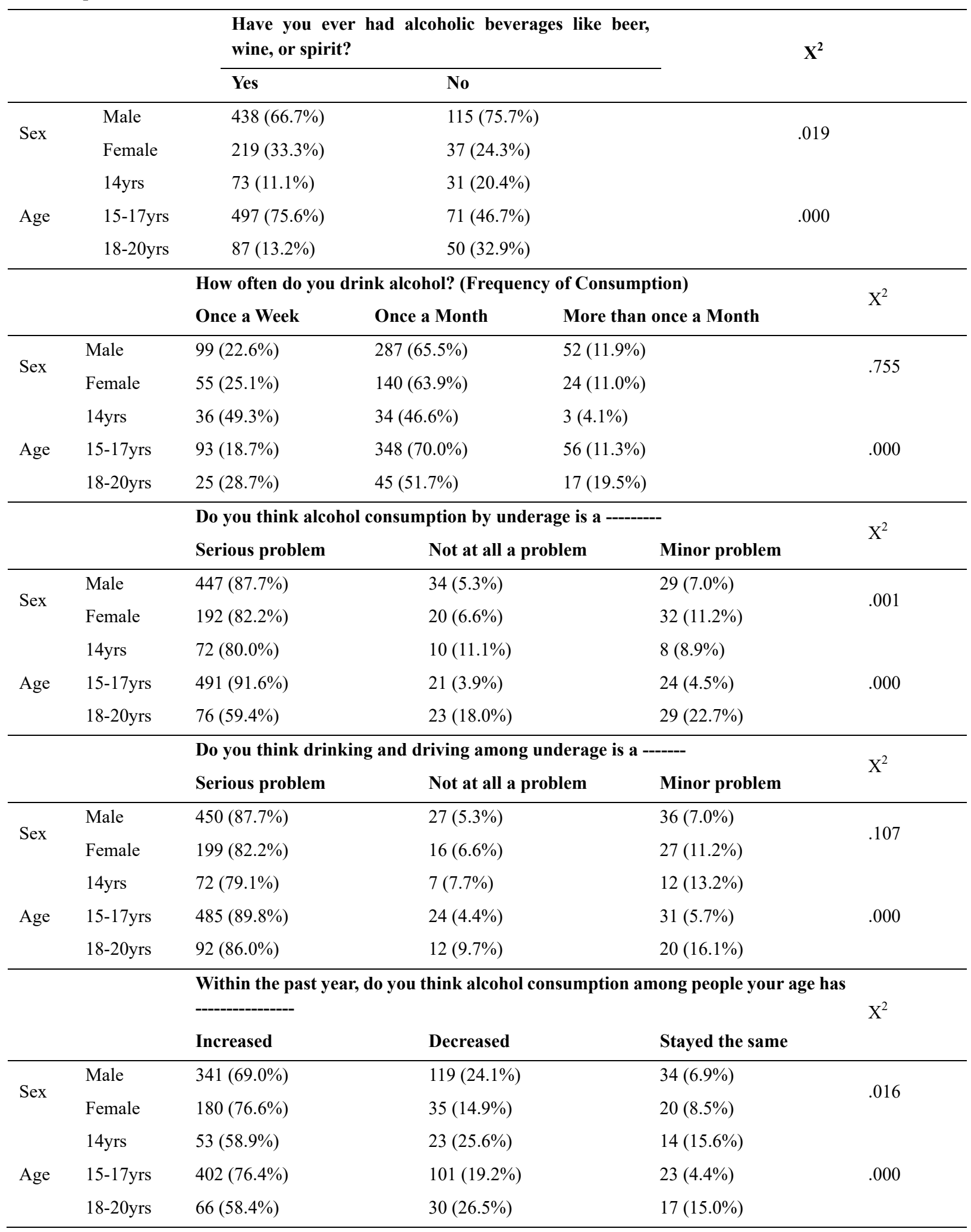

$65.5 \%$ of male and respondents between ages 15 and 17 (70\%) drink once a month. More females $(25.1 \%)$ than males $(22.6 \%)$ drink once a week. Only few respondents across gender and age drink more than once a month. Alcohol was seen as a major problem by the respondents with $87.7 \%$ of male and $82.2 \%$ of females respectively. 
All the age categories ( 14 years $-80 \%$; $15-17$ years $-91.6 \%$; $18-20$ years $-59.4 \%$ ) perceive alcohol consumption among underage as a serious problem. The respondents displayed good knowledge of the negative influence of alcohol consumption on driving. When asked "do you think drinking and driving constitute a serious, minor or no problem at all, $89.8 \%$ of $15-17$ year olds, $87.7 \%$ of male and $82.8 \%$ of female respondents agreed it was a serious problem. The same trend was observed among the 14 year olds $(79.1 \%)$ and $18-20$ year olds $(86 \%)$. On the question of heavy use of alcohol within the past year, females (76.6\%), males (69\%), and $15-17$ year olds (76.4\%) reported that there is increased while $24 \%$ of male respondents 25.6 of the 14 years olds and about $27 \%$ of the 18 20 year olds reported that it is decreasing.

Table 6. Description of other Variables

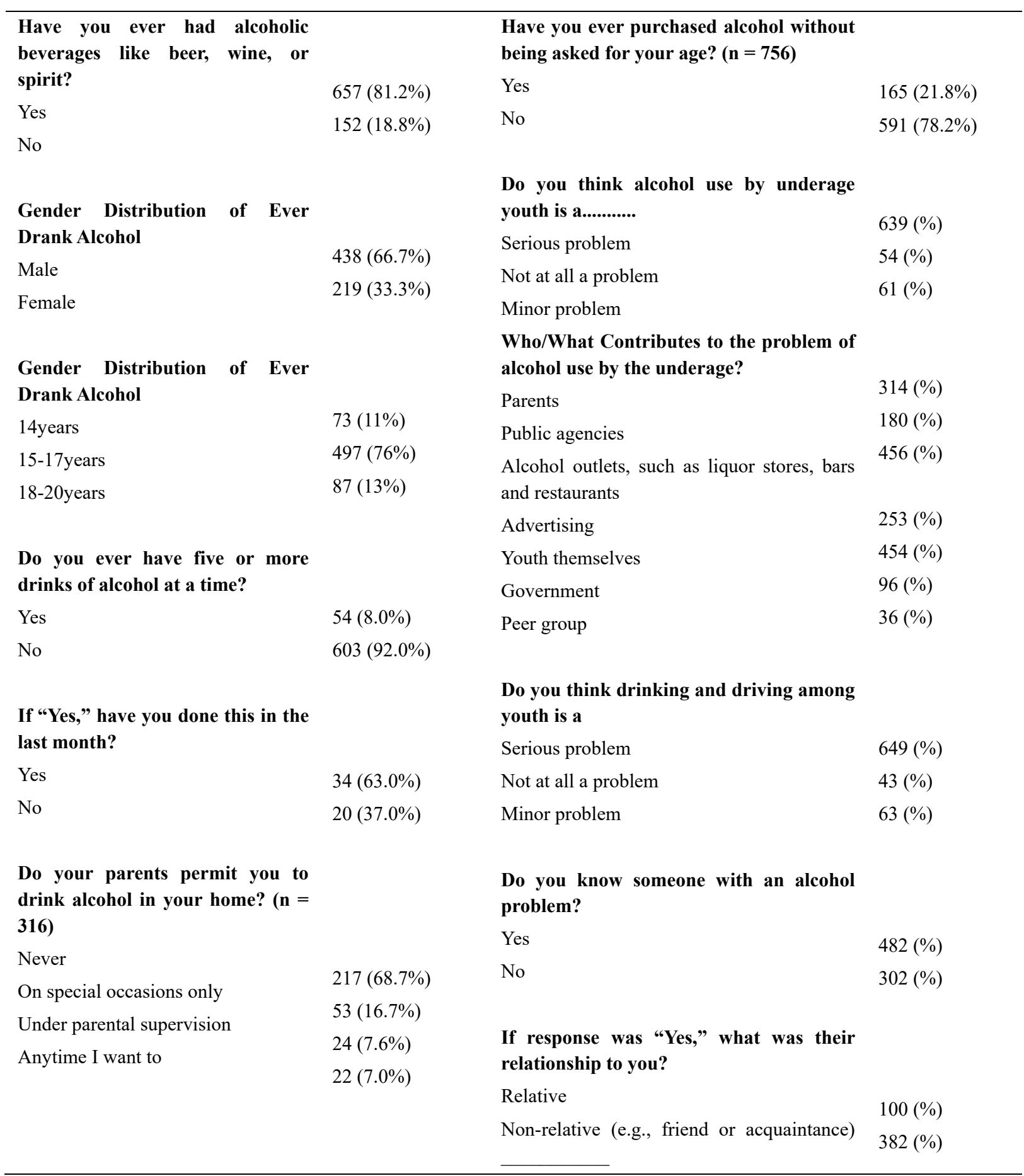




Do you discuss alcohol use with
your parent(s)? $(\mathbf{n}=\mathbf{3 5 4})$
Yes
No
Do your parents know how much
you drink? $(\mathbf{n}=\mathbf{3 3 5})$
Yes
No

Have your parents ever seen you drunk? $(n=351)$

Yes

No

\begin{abstract}
How many times in the last two months has someone offered to give you, buy for you, or sell you alcohol? )
\end{abstract}

None

Once

2-3 times

4 or more times

$\begin{array}{lc}\text { Sources where underage obtain alcohol? } & \\ \text { Parent's home } & 107(13.2 \%) \\ \text { Liquor store } & 175(21.6 \%) \\ \text { Bar/restaurant } & 320(39.6 \%) \\ \text { Supermarket/convenience store } & 16(2.0 \%) \\ \text { Friends/relatives } & 169(20.9 \%) \\ \text { Other } & 20(2.5 \%)\end{array}$

$77(23.0 \%)$

$258(77.0 \%)$

Have you successfully used a fake age to obtain alcohol? $(\mathrm{n}=)$

Yes

$47(13.4 \%)$

No

$325(\%)$

$304(86.6 \%)$

Do you know of parents or adults who permit non-family members under the age of 21 to consume alcohol in their homes? $(\mathbf{n}=)$

Yes $173(\%)$

No

$161(\%)$

In Table 6, of the 809 respondents, 657 (81.2\%) had ever drank alcohol and of this are $438(66.7 \%)$ males and 219 $(33.3 \%)$ females. For the age distribution of the ever drank, 497 (76\%) are in the 15-17 years age bracket while 73 $(11 \%)$ and $87(13 \%)$ are in the 14 years and 18-20 years age category. Respondents report on whether parents permit them to drink at home show that parents never permitted alcohol consumption [217 (68.7\%)] while 53 $(16.7 \%)$ reported that they are allowed to drink on special occasions only. $24(7.6 \%)$ and $22(7.0 \%)$ reported that they drink under parental supervision and anytime they want to drink respectively. $116(33 \%)$ of the respondents engage with their parents in discussing alcohol use while 238 (67\%) do not. Of the 335 that responded to this item, $77 \%$ reported that their parents do not know how much they drink while $13.4 \%$ reported that parents have seen them drunk. 21.8\% have bought alcohol without being asked of their age. This is similar to report from Yoon, Lam, Sham and Lam (2017). They reported that Chinese teen drinkers often convince vendors that they were of legal drinking age to source alcohol.

\section{Discussion}

On the frequency of alcohol use, report revealed that $154(23.4 \%)$ drink at least once in a week while $76(11.6 \%)$ drink more than once in a month. Majority of those who drink reported drinking at least once in a month $(65 \%)$. This shows a relatively low rate of alcohol consumption when compared to data from other sources. For example, in a Finnish sample, $78 \%$ of boys and $79 \%$ of girls aged 18 years said they drink alcohol at least once a month. In the same year, $18 \%$ of girls and $22 \%$ of boys aged 16 years reported drinking once a month or more (Ministry of Social Affairs and Health, 2006). In this study, the respondents reported that their peers drink because they want to have a good time at a party $(26 \%)$, to deal with sadness or depression $(24 \%)$ and they wish to fit in or be accepted by their friends or peers (24\%). However, in a study by Adekeye (2012), it was found that the main reasons for student's drinking were because friends (peers) drink (77\%), curiosity (63\%), because drinks are readily available $(27 \%)$, and to get away from worries $(23 \%)$.

A review of 22 studies examining parental monitoring and alcohol use showed that increased parental monitoring is significantly associated with later alcohol initiation and decreased alcohol use (Ryan, Jorm, \& Lubman, 2010). In the US, studies indicated that increased parental monitoring is associated with reduced alcohol use and the possible negative consequences of use among adolescents (Bourdeau et al., 2011; Stone, Becker, Huber, \& Catalano, 2012; Walls, Fairlie, \& Wood, 2009). 
On the effects of alcohol, underage drinkers (24\%) reported been a passenger in a vehicle in which the driver was under the influence of alcohol, $22.7 \%$ went on to report being absent from school because of alcohol use while others reported been drunk at parties (20\%). There are several contributing factors to alcohol use by students. Correia, Murphy and Barnett (2012) listed among other factors cultural norms, expectations on benefits of drinking, parent's attitude towards drinking and affordability of alcohol. All these result to a culture of drinking (Obot, 2000) that can be harmful to the students. Various researches have shown that drinking among youths is done excessively and this lowers their ability to make decisions, control their impulse, or drive a car and fades their memories.

According to Vorvick (2016), Newbury-Birch, Walker, Avery, Beyer, Brown, Jackson, Lock, McGovern, \& Kaner, (2008), Sincelar, Barnett and Spirito, (2004), the havoc of underage drinking include falls, car crashes, weight loss, disturbed sleep, headaches, drowning, various accidents, suicide, violence, homicide, increase in addiction, sexual assault or rape, engage in unprotected sex or have multiple sex partners, unwanted pregnancy, damage of brain cells which can lead to lasting damage to memory, thinking and judgment or decision making, poor academic performance, depression, low self-esteem, serious injury and ultimately death. Office for National Statistics (2017) corroborates the above findings that in Britain, significant number of people are now dying with alcoholic liver disease in their twenties, what a pity.

On the approach and strategies to reduce consumption of alcohol, $73 \%$ of the under aged agreed that there should be more alcohol education in schools while about $67 \%$ felt there should be more alcohol education in the mass media. A qualitative study by Coleman and Cater (2009) argued the case for the compulsory inclusion of alcohol education in schools, and structural reforms to encourage a change in the binge-drinking culture. In measuring binge drinking, which is the consumption of excessive alcohol in a single drinking episode, it was phrased as do you ever have five or more drinks of alcohol at a time? It is dangerous because in most cases it becomes more and more frequent which leads to addiction. In a more accurate perspective, binge drinking is taking more alcohol than is recommended by doctors and taking the UK as an example, it is taking more than 64 grams or 4 beer cans for a man and more than 48 grams or three beer cans for a woman (Coomber, Mcelrath, Measham, \& Moore, 2013). A qualitative study by Coleman and Cater (2009) examined young people's perceived motivations for 'binge' drinking, and the associated harmful outcomes among14 to 17 year olds in southern England who had experience of binge drinking. Given the underage sample, most of this drinking occurred in unsupervised, outdoor locations. It seems that making the transition to drinking in pubs/bars, offers a protective factor for a number of risky outcomes. For example, Hingson, Heeren, Zakocs, Kopstein and Wechsler (2002) estimated that approximately $42 \%$, or over 3 million of the 8 million students attending colleges in the U.S. have consumed five or more drinks during a single drinking occasion within the past 30 days.

\section{Conclusion}

To salvage the destiny of the underage, parents and significant care givers should discourage the act of drinking, create great awareness on the dangers of drinking let alone underage participation, serve as positive models, prevent the availability of alcohols to underage at parties, school, homes, or supervise all parties to ensure there is no alcohol, promote healthy activities or gathering that will not involve alcohol.

\section{Competing Interests Statement}

The authors declare that there are no competing or potential conflicts of interest.

\section{References}

Adekeye, O. A. (2005). Adolescents and the HIV pandemic. Ilorin Researcher, 6(1), 1-11

Adekeye, O. A. (2012). Knowledge Level and Attitude of School Going Male Adolescents towards Drug Use and Abuse. Kotangora Journal of Education. Kotangora, Niger State, 12, 122-130.

Adekeye, O. A., Adeusi, S. O., Chenube, O. O., Ahmadu, F. O., \& Sholarin, M. A. (2015). Assessment of Alcohol and Substance Use among Undergraduates in Selected Private Universities in Southwest Nigeria. IOSR Journal of Humanities and Social Science (IOSR-JHSS), 20(3), 1-7. Retrieved from http://www.iosrjournals.org/iosr-jhss/pages/20\%283\%29Version-2.html.

Adekeye, O. A., Odukoya, J. D., Chenube, O. O., Igbokwe, D. O., Igbinoba, A., \& Olowookere, E. I. (2017). Subjective Experiences and Meaning Associated with Drug Use and Addiction: A Mixed Method Approach. Global Journal of Health Science, 9(8), 57-65. https://doi.org/10.5539/gjhs.v9n8p57

Adekeye, O. A., Amoo, E. O., Adeusi, S. O., Chenube, O. O., Ahmadu, F., \& Idoko, J. (2019). Dataset on Perception of Public College Students on Underage Drinking in Nigeria. Data in Brief, Vol. 24. 
https://doi.org/10.1016/j.dib.2019.103930

Bourdeau, B., Miller, B. A., Duke, M. R., \& Ames, G. M. (2011). Parental strategies for knowledge of adolescents' friends: distinct from monitoring? Journal of Child and Family Studies, 20(6), 814-821. https://doi.org/10.1007/s10826-011-9449-0

Centers for Disease Control and Prevention, (CDC, 2016). Fact Sheets: Underage Drinking. Atlanta, GA: retrieved from http://www.cdc.gov/alcohol/fact-sheets/underage-drinking.htm.

Centers for Disease Control and Prevention. (2015). Youth online: Results from the 2015 Middle School Youth Risk Behavior Survey. Retrieved from https://need.cdc.gov/youthonline/App/Default.aspx?SID=MS.

Coleman, L., \& Cater, S. (2009). Underage 'binge' drinking: A qualitative study into motivations and outcomes (pp. 125-136). https://doi.org/10.1080/09687630512331323521

Coomber, R., Mcelrath, K., Measham, F., \& Moore, K. (2013). Key Concepts in Drugs and Society. SAGE Publications Ltd. https://doi.org/10.4135/9781526401670

Cooper, M. L., \& Orcutt, H. K. (1997). Drinking and sexual experience on first dates among adolescents. Journal of Abnormal Psychology, 106(1997), 191-202. https://doi.org/10.1037/0021-843X.106.2.191

Cooper, M. L., Pierce, R. S., \& Huselid, R. F. (1994). Substance use and sexual risk taking among black adolescents and white adolescents. Health Psychology, 13(1994), 251-262. https://doi.org/10.1037/0278-6133.13.3.251

Correia, C. J., Murphy, J. G., \& Barnett, N. P. (2012). College Student Alcohol Abuse: A Guide to Assessment, Intervention, and Prevention. Somerset, NJ, USA: John Wiley \& Sons.

Grant, B. F., \& Dawson, D. A. (1997). Age at Onset of Alcohol Use and Its Association with DSM-IV Alcohol Abuse and Dependence: Results from the National Longitudinal Alcohol Epidemiologic Survey National Institute on Alcohol Abuse and Alcoholism. Journal of Substance Abuse, 9, 103-110. https://doi.org/10.1016/S0899-3289(97)90009-2

Guardian Newspapers. (2018). Underage Drinking: Guinness, Others Lead War Against Menace. Retrieved from https://guardian.ng/business-services/underage-drinking-guinness-others-lead-war-against-menace/

Health and Social Care Information Centre, (HSCIC, 2015). Smoking, Drinking and Drug Use Among Young People in England - 2014, Retrieved from http://www.ias.org.uk/Alcohol-knowledge-centre/Underage-drinking/Factsheets/Prevalence-of-underage-dri nking.aspx

Hibell, B., Guttormsson, U., Ahlström, S., Balakireva, O., Bjarnason, T., Kokkevi, A., \& Kraus, L. (2012). The 2011 ESPAD Report: Substance Use Among Students in 36 European Countries. Stockholm: The Swedish Council for Information on Alcohol and Other Drugs (CAN).

Hingson, R. W., Heeren, T., Zakocs, R. C., Kopstein, J., \& Wechsler, H. (2002). Magnitude of alcohol-related mortality and morbidity among U.S. college students ages 18-24. Journal of Studies on Alcohol, 63, 136-144. https://doi.org/10.15288/jsa.2002.63.136

Information Services Division Scotland. (2014), Scottish Schools Adolescent Lifestyle and Substance Use Survey.

Ipsos MORI. (2016). Drinkaware Monitor 2016: Teenage drinking and the role of parents and guardians [Online] retrieved from https://www.drinkaware.co.uk/media/1764/drinkaware-monitor-report-2016.pdf.

Jernigan, D. H. (2001). Global Status Report: Alcohol and Young People. World Health.

Keller, M., \& Vaillant, G. E. (2011). Alcohol consumption. Encyclopedia Britannica Online. Retrieved from http://www.britannica.com/EBchecked/topic/13398/alcohol-consumption

Loukas, A., Cance, J. D., \& Batanova, M. (2016). Trajectories of school connectedness across the middle school years: Examining the roles of adolescents' internalizing and externalizing problems. Youth \& Society, 48(4), 557-567. https://doi.org/10.1177/0044118X13504419

Ministry of Social Affairs and Health. (2006). Helsinki University Printing house. Use of Tobacco products, Alcohol use and exposure to drugs in 1977-2005.

Morgan, S. L., \& Todd, J. J. (2009). Intergenerational closure and academic achievement in high school: A new evaluation of Coleman's conjecture. Sociology of Education, 82, 267-286. https://doi.org/10.1177/003804070908200304 
Newbury-Birch, D., Walker, J., Avery, L., Beyer, F., Brown, N., Jackson, K., Lock, C. A. et al. (2008). Impact of Alcohol Consumption on Young People: A Systematic Review of Published Reviews. Retrieved from http://dera.ioe.ac.uk/11355/1/DCSF-RR067.pdf

Obot, I. S. (2000). The measurement of drinking patterns and alcohol problems in Nigeria. Journal of Substance Abuse, 12, 169-181. https://doi.org/10.1016/S0899-3289(00)00047-X

Odukoya, J. A., Adekeye, O. A., Igbinoba, A. O., \& Afolabi, A. (2018). Item analysis of university-wide multiple choice objective examinations: the experience of a Nigerian private university. Quality and Quantity. International Journal of Methodology, 52(3), 983-997. https://doi.org/10.1007/s11135-017-0499-2

Office for National Statistics. (2017). Alcohol-Related Deaths in the UK, 2015. Retrieved from https://www.ons.gov.uk/peoplepopulationandcommunity/healthandsocialcare/causesofdeath/datasets/alcoho lrelateddeathsbysexagegroupandindividualcauseofdeath

Okeh, V. (2018). Guinness Nigeria Rolls Out Campaign to Tackle Under-Age Drinking in Lagos Schools. Retrieved from https://bizwatchnigeria.ng/guinness-nigeria-rolls-out-campaign-to-tackle-under-agedrinking-in-lagos-schools/

Ryan, S. M., Jorm, A. F., \& Lubman, D. I. (2010). Parenting factors associated with reduced adolescent alcohol use: a systematic review of longitudinal studies. The Australian and New Zealand Journal of Psychiatry, 44(9), 774-783. https://doi.org/10.1080/00048674.2010.501759

Sincelar, H. A., Barnett, N., \& Spirito, A. (2004). Adolescent Alcohol Use and Injury: A Summary and Critical Review of the Literature.

Stone, A. L., Becker, L. G., Huber, A. M., \& Catalano, R. F. (2012). Review of risk and protective factors of substance use and problem use in emerging adulthood. Addictive Behaviors, 37(7), 747-775. https://doi.org/10.1016/j.addbeh.2012.02.014

Substance Abuse and Mental Health Services Administration. (SAMHSA, 2016). 2015 National Survey on Drug Use and Health (NSDUH). Rockville, MD: SAMHSA, 2016. Retrieved from http://www.samhsa.gov/data/sites/default/files/NSDUH-DetTabs-2015/NSDUH-DetTabs-2015/NSDUH-De tTabs-2015.htm\#tab2-19b.

Substance Abuse and Mental Health Services Administration. (SAMHSA, 2016). 2015 Key Substance Use and Mental Health Indicators in the United States: Results from the 2015 National Survey on Drug Use and Health. Rockville, MD: SAMHSA, 2016. Retrieved from http://www.samhsa.gov/data/sites/default/files/NSDUH-FFR1-2015/NSDUH-FFR1-2015/NSDUH-FFR1-2 015.htm\#fig24.

Victorian Youth Alcohol and Drug Survey. (2009). Teen drinking law. Retrieved from http://teendrinkinglaw.vic.gov.au/parents/young_how_much.php

Vorvick, L. J. (2016). Risks of underage drinking. Retrieved from https://medlineplus.gov/ency/patientinstructions/000528.htm

Walls, T. A., Fairlie, A. M., \& Wood, M. D. (2009). Parents do matter: a longitudinal two-part mixed model of early college alcohol participation and intensity. Journal of Studies on Alcohol and Drugs, 70(6), 908-918. https://doi.org/10.15288/jsad.2009.70.908

Yoon, S., Lam, W., Sham, W. T., \& Lam, T. H. (2017). Underage drinking, group identity and access to alcohol: a qualitative study of Chinese youths. Health Education Research, 32(3), 269-278. https://doi.org/10.1093/her/cyx045

\section{Copyrights}

Copyright for this article is retained by the author(s), with first publication rights granted to the journal.

This is an open-access article distributed under the terms and conditions of the Creative Commons Attribution license (http://creativecommons.org/licenses/by/4.0/). 